\title{
Simulation and Analysis of Optimum Golomb Ruler based 2D Codes for OCDMA System
}

\author{
Dr. Gurjit Kaur \\ Department of ECE \\ Gautam Buddha University, Greater Noida, \\ U. P., India \\ Rajesh Yadav \\ Department of ECE \\ Gautam Buddha University, Greater Noida, \\ U. P., India
Disha Srivastava
Department of ECE,
Gautam Buddha University, Greater Noida, U. P., India

\author{
Aarti Bhardwaj \\ Department of ECE \\ Gautam Buddha University, Greater Noida, \\ U. P., India \\ Manu Gangwar \\ Department of ECE \\ Gautam Buddha University, Greater Noida, \\ U. P., India \\ Nidhi \\ Department of ECE, \\ Gautam Buddha University, Greater Noida, \\ U. P., India
}

\begin{abstract}
The need for high speed communications networks has led the research communities and industry to develop reliable, scalable transatlantic and transpacific fiber-optic communication links. In this paper the optimum Golomb ruler based 2D OCDMA codes has been demonstrated. An OCDMA system based on the discussed $2 D$ codes is designed and simulated on Optisystem. The encoder and decoder structure of OCDMA system have been designed using filter and time delays. Further the performance is analysed for various parameter such as bit rate, number of users, BER (Bit Error Rate), quality factor, eye diagram and signal diagram. The system is analyzed for up to 18 users at $1 \mathrm{Gbps}$ and $1.25 \mathrm{Gbps}$ bit rate.
\end{abstract}

Keywords-OCDMA System; 2D Codes; OOC; Golomb Ruler; BER; Eye Diagram; MAI

\section{INTRODUCTION}

In Local Area Networks (LANs), since the traffic is bursty, it demands high speed and large capacity communication network. The optical fiber addresses these requirements because the bandwidth of optical fiber is enormous and it can provide higher carrier frequency and therefore greater information carrying capacity of the communication and higher transmission bandwidth for the communication [1]. There are various multiple access techniques [2] which are being used to accommodate the large number of users such as Optical Code Division Multiple Access (OCDMA). The OCDMA system plays an essential role in long haul and high speed communication where users share the same transmission media [3] as shown in Figure 1.

In OCDMA each user is assigned a unique signature code which is modulated by the data of the corresponding user. The signal from all the users is combined on a single optical fiber, which is broadcasted to each user in the network. Single-user decoding is achieved by correlating the aggregate signal and the signature sequence of the desired user. If the output of the decoder is in autocorrelation then the receiver can detect the signal sent to it. On the other hand, if the decoder is in cross correlation then the receiver cannot receive the signal. For OCDMA systems, optical codes should have maximum autocorrelation and minimum cross correlation property.

As the number of user increases the Multiple Access Interference (MAI) also increases and this is the main cause of performance degradation in OCDMA network. So cross correlation is needed to be kept less for maintaining probability of error low. Many codes have been proposed for the OCDMA system. Mendez et al. presented the one dimensional optical orthogonal code [4].

In one dimensional (1-D) codes, on increasing the number of users, the length of the codes also increases. And hence, the bit rate decreases for a given chip width [5]. To overcome this problem of 1-D codes in OCDMA, two dimensional (2-D) codes have been proposed such as Time-Space (T/S) and Wavelength-Time (W/T). 


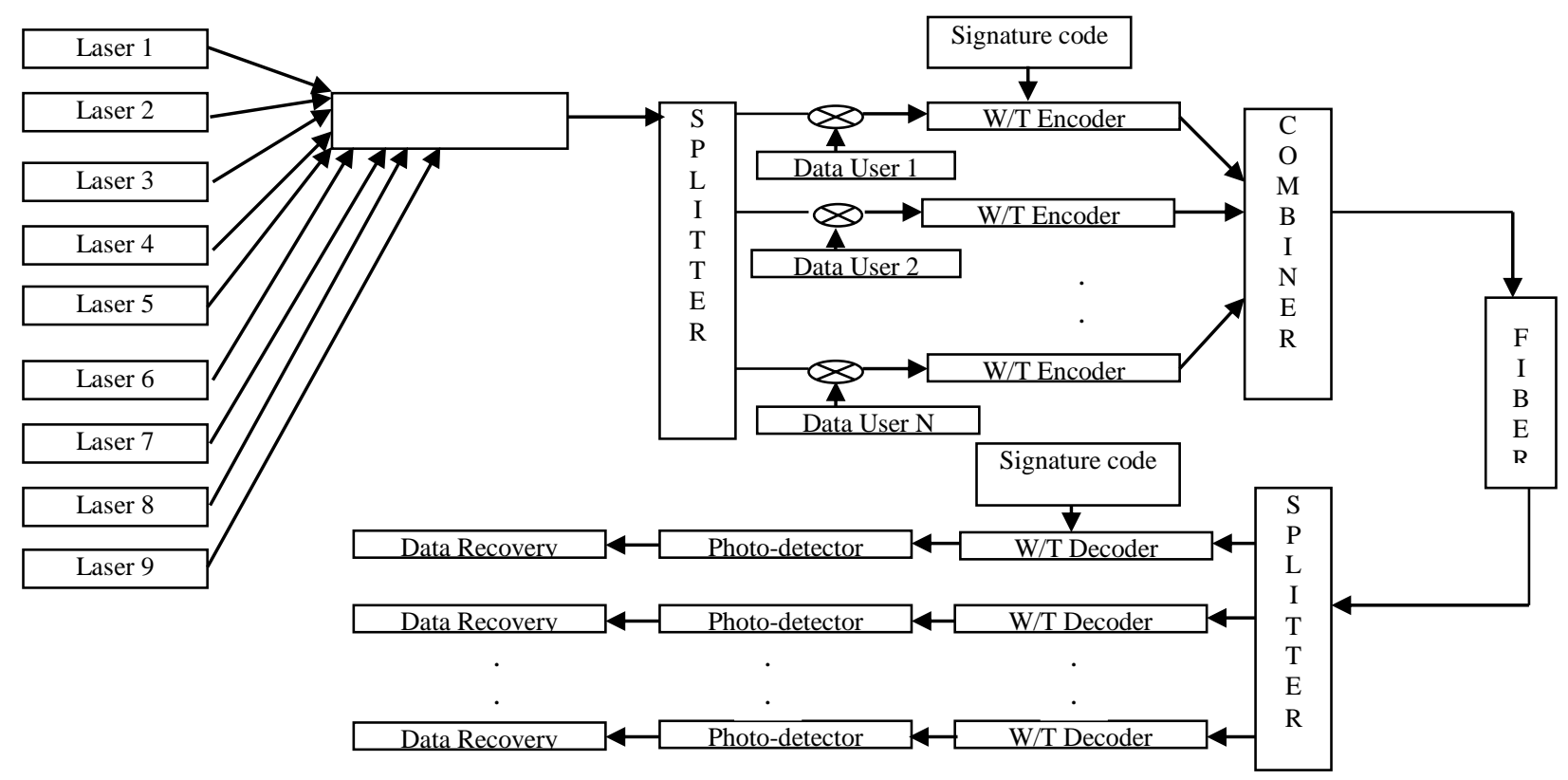

Fig. 1. OCDMA system Block Diagram

Heo have proposed the construction of 2-D wavelengthtime codes by hybridization of the prime codes and the pseudorandom noise codes using differential detection with on-off keying [6]. Yeon have designed modified pseudo-random noise codes for W/T spreading with two sequences having different lengths [7]. Wan and Hu have constructed hybrid codes by concatenating the prime codes and optical orthogonal codes[8]. Mendez construct 2-D codes from 1-D Golomb rulers to increase the number of code set size [9]. In 2D optical codes, the length of the codes reduces and hence improves the BER performance. Large numbers of researchers are working on the design of 2D codes for OCDMA system [9 - 10]. In this paper, the design of Optical Orthogonal Codes (OOC) using optimum Golomb rulers has been demonstrated and the OCDMA system performance on Optisystem tool has been analyzed.

The rest of paper is organized as follows: Section II discusses the OCDMA coding theory that gives an insight of the optical codes for optical CDMA communication system. The mathematical modeling of proposed 2D optical code is described. Section III presents a concise introduction to optical OCDMA systems for simulation. Section IV discusses the result of the proposed optical prime codes and its performance estimation in terms of the autocorrelation and cross-correlation function. In section $\mathrm{V}$ the current findings along with the future directions are concluded. The paper ends with the references studied and cited in the paper.

\section{OPTICAL CODING THeORY}

\section{A. Construction of codes}

The W/T code can be represented as matrices with wavelength and time as axis. This matrix is known as Pseudo Orthogonal (PSO) matrix code. Total wavelength is divided into $\mathrm{n}$ different channels and total time is divided into $\mathrm{m}$ time slots. These PSO matrix codes are constructed with the help of spanning ruler or optimum Golomb ruler [11].
$\mathrm{N}$-mark Golomb ruler is a set of $\mathrm{n}$ distinct non negative integers $\left(a_{1}, a_{2}, a_{3}, \ldots . . a_{n}\right)$ called "marks" such that the positive differences $\left|a_{i}-a_{j}\right|$ computed over all possible pairs of different integers $i, j=1,2,3 \ldots . . n$ with $i \neq j$, are distinct.

A perfect Golomb ruler of order (mark) 4 and length 6 is shown in Figure 2. It is not possible to have another type of perfect ruler. So this ruler is Optimum Golomb ruler in which the distance between the two points is unique.The optimum Golomb ruler $g(1,7)$ of weight 7 , length 26 and cardinality (number of user) 1 is shown in Figure 3. Figure 4 represents the construction of 4 code matrices M1...M4 from shifted version of Golomb ruler $\mathrm{g}(1,7)$ with filler zeros (shown) that increases the code dimension.

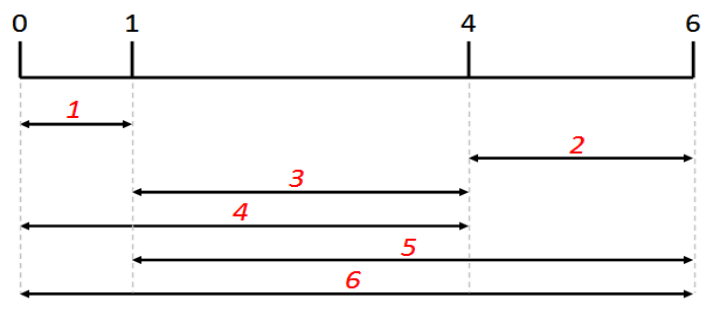

Fig. 2. Golomb ruler of order 4

The headings of table in Figure 4(a) define the column and row to which the table entries should be transposed. These matrices can be converted into 2D W/T codes by taking row as $\mathrm{i}^{\text {th }}$ wavelength and column as $\mathrm{j}^{\text {th }}$ time slot as shown in Figure 4(b). For example for matrix M4, the code will be $\left\{\lambda_{4}: \lambda_{2}: \_: \lambda_{2}: \lambda_{4}: \_: \lambda_{1}: \lambda_{1}\right\}$ which signifies fourth wavelength in first time slot, second wavelength in second time slot, second wavelength in fourth time slot, fourth wavelength in fifth time slot, first wavelength in seventh and eighth time slot. 


\begin{tabular}{|l|l|l|l|l|l|l|l|l|l|l|l|l|l|l|l|l|l|l|l|l|l|l|l|l|l|}
\hline 1 & 0 & 1 & 1 & 0 & 0 & 0 & 0 & 0 & 0 & 1 & 0 & 0 & 0 & 0 & 0 & 1 & 0 & 0 & 0 & 0 & 1 & 0 & 0 & 0 & 1 \\
\hline
\end{tabular}

Fig. 3. Optimum Golomb ruler $g(1,7)$ of weight 7 , length 26 and cardinality 1

\begin{tabular}{|c|c|c|c|c|c|c|c|c|c|c|c|c|c|c|c|c|c|c|c|c|c|c|c|c|c|c|c|c|c|c|c|c|}
\hline \multirow[b]{2}{*}{$\mathbf{M}$} & \multicolumn{4}{|c|}{ Column1 } & \multicolumn{4}{|c|}{ Column2 } & \multicolumn{4}{|c|}{ Column3 } & \multicolumn{4}{|c|}{ Column4 } & \multicolumn{4}{|c|}{ Column5 } & \multicolumn{4}{|c|}{ Column6 } & \multicolumn{4}{|c|}{ Column7 } & \multicolumn{4}{|c|}{ Column8 } \\
\hline & R1 & $\mathbf{R 2}$ & R3 & R4 & R1 & $\mathbf{R 2}$ & R3 & R4 & R1 & R2 & R3 & R4 & R1 & R2 & R3 & R4 & R1 & $\mathbf{R 2}$ & R3 & R4 & R1 & R2 & $\mathbf{R 3}$ & R4 & R1 & R2 & R3 & R4 & R1 & $\mathbf{R 2}$ & R3 & R4 \\
\hline 1 & 1 & 0 & 1 & 1 & 0 & 0 & 0 & 0 & 0 & 0 & 1 & 0 & 0 & 0 & 0 & 0 & 1 & 0 & 0 & 0 & 0 & 1 & 0 & 0 & 0 & 1 & 0 & 0 & 0 & 0 & 0 & 0 \\
\hline 2 & 0 & 1 & 0 & 1 & 0 & 0 & 0 & 0 & 0 & 0 & 0 & 1 & 0 & 0 & 0 & 0 & 0 & 1 & 0 & 0 & 0 & 0 & 1 & 0 & 0 & 0 & 1 & 0 & 0 & 0 & 0 & 0 \\
\hline 3 & 0 & 0 & 1 & 0 & 1 & 0 & 0 & 0 & 0 & 0 & 0 & 0 & 1 & 0 & 0 & 0 & 0 & 0 & 1 & 0 & 0 & 0 & 0 & 1 & 0 & 0 & 0 & 1 & 0 & 0 & 0 & 0 \\
\hline 4 & 0 & 0 & 0 & 1 & 0 & 1 & 0 & 0 & 0 & 0 & 0 & 0 & 0 & 1 & 0 & 0 & 0 & 0 & 0 & 1 & 0 & 0 & 0 & 0 & 1 & 0 & 0 & 0 & 1 & 0 & 0 & 0 \\
\hline
\end{tabular}

Fig. 4. (a): Construction of code matrices

\begin{tabular}{l|l|c|c|c|c|c|c|c|c|}
\hline & M1 & C1 & C2 & $\mathrm{C} 3$ & $\mathrm{C} 4$ & $\mathrm{C} 5$ & $\mathrm{C} 6$ & $\mathrm{C} 7$ & $\mathrm{C} 8$ \\
\hline $\mathrm{r} 1$ & 1 & 0 & 0 & 0 & 1 & 0 & 0 & 0 \\
\hline $\mathrm{r} 2$ & 0 & 0 & 0 & 0 & 0 & 1 & 1 & 0 \\
\hline $\mathrm{r} 3$ & 1 & 0 & 1 & 0 & 0 & 0 & 0 & 0 \\
\hline $\mathrm{r} 4$ & 1 & 0 & 0 & 0 & 0 & 0 & 0 & 0 \\
\hline
\end{tabular}

$\mathrm{M} 3=$

\begin{tabular}{|c|c|c|c|c|c|c|c|c|c|}
\hline & $\mathrm{C} 1$ & $\mathrm{C} 2$ & $\mathrm{C} 3$ & $\mathrm{C} 4$ & $\mathrm{C} 5$ & $\mathrm{C} 6$ & $\mathrm{C} 7$ & $\mathrm{C} 8$ \\
\hline $\mathrm{r} 1$ & 0 & 1 & 1 & 0 & 1 & 0 & 0 & 0 \\
\hline $\mathrm{r} 2$ & 0 & 0 & 0 & 0 & 0 & 0 & 0 & 0 \\
\hline $\mathrm{r} 3$ & 1 & 0 & 0 & 0 & 0 & 1 & 0 & 0 \\
\hline $\mathrm{r} 4$ & 0 & 0 & 0 & 0 & 0 & 0 & 1 & 0 \\
\hline
\end{tabular}

\begin{tabular}{|c|c|c|c|c|c|c|c|c|c|}
\hline \multirow[t]{5}{*}{$\mathrm{M} 2=$} & \multicolumn{9}{|c|}{\begin{tabular}{|l|l|l|l|l|l|l|l|}
$\mathrm{C} 1$ & $\mathrm{C} 2$ & $\mathrm{C} 3$ & $\mathrm{C} 4$ & $\mathrm{C} 5$ & $\mathrm{C} 6$ & $\mathrm{C} 7$ & $\mathrm{C} 8$
\end{tabular}} \\
\hline & $\mathrm{r} 1$ & 0 & 0 & 0 & 0 & 0 & 0 & 0 & 0 \\
\hline & $\mathrm{r} 2$ & 1 & 0 & 0 & 0 & 1 & 0 & 0 & 0 \\
\hline & $\mathrm{r} 3$ & 0 & 0 & 0 & 0 & 0 & 1 & 1 & 0 \\
\hline & $\mathrm{r} 4$ & 1 & 0 & 1 & 0 & 0 & 0 & 0 & 0 \\
\hline \multirow{5}{*}{ M4 = } & \multicolumn{9}{|c|}{\begin{tabular}{|l|l|l|l|l|l|l|l|}
$\mathrm{C} 1$ & $\mathrm{C} 2$ & $\mathrm{C} 3$ & $\mathrm{C} 4$ & $\mathrm{C} 5$ & $\mathrm{C} 6$ & $\mathrm{C} 7$ & $\mathrm{C} 8$ \\
\end{tabular}} \\
\hline & $\mathrm{r} 1$ & 0 & 0 & 0 & 0 & 0 & 0 & 1 & 1 \\
\hline & $\mathrm{r} 2$ & 0 & 1 & 0 & 1 & 0 & 0 & 0 & 0 \\
\hline & $\mathrm{r} 3$ & 0 & 0 & 0 & 0 & 0 & 0 & 0 & 0 \\
\hline & $\mathrm{r} 4$ & 1 & 0 & 0 & 0 & 1 & 0 & 0 & 0 \\
\hline
\end{tabular}

Fig. 4. (b): Construction of code matrices

Now the concept of folded optimum Golomb ruler has been expended by using more than one optimum Golomb ruler as shown in Figure 5 and design a matrix with eight wavelength
( 8 rows) and four time slots ( 4 columns) that can produce $(8 \times 4)$ $=32$ Pseudo Orthogonal (PSO) codes as represented in Figure 6 . It should be noted that the cardinality goes from 4 to 32 .

$$
\begin{aligned}
& \begin{array}{|l|l|l|l|l|l|l|l|l|l|l|l|l|l|l|l|l|l|l|l|l|l|l|l|}
\hline 1 & 0 & 0 & 0 & 0 & 0 & 0 & 0 & 0 & 1 & 0 & 0 & 0 & 0 & 1 & 0 & 0 & 0 & 0 & 0 & 0 & 1 & 0 & 0 \\
\hline
\end{array} \\
& \begin{array}{|l|l|l|l|l|l|l|l|l|l|l|l|l|l|l|l|l|l|l|l|l|l|l|l|l|}
\hline 1 & 0 & 0 & 0 & 0 & 0 & 0 & 0 & 1 & 0 & 0 & 0 & 0 & 0 & 0 & 0 & 0 & 0 & 1 & 0 & 0 & 0 & 0 & 0 & 1 \\
\hline
\end{array} \\
& \begin{array}{|l|l|l|l|l|l|l|l|l|l|l|l|l|l|l|l|l|l|l|l|l|l|l|l|l|}
\hline 1 & 0 & 0 & 1 & 0 & 0 & 0 & 0 & 0 & 0 & 0 & 0 & 0 & 0 & 0 & 0 & 0 & 0 & 0 & 0 & 0 & 0 & 1 & 1 & 0 \\
\hline
\end{array} \\
& \begin{array}{|l|l|l|l|l|l|l|l|l|l|l|l|l|l|l|l|l|l|l|l|l|l|l|l|l|}
\hline 1 & 0 & 0 & 0 & 1 & 0 & 0 & 0 & 0 & 0 & 0 & 0 & 0 & 0 & 0 & 1 & 0 & 1 & 0 & 0 & 0 & 0 & 0 & 0 & 0 \\
\hline
\end{array}
\end{aligned}
$$

\begin{tabular}{|c|c|c|c|c|c|c|c|c|c|c|c|c|c|c|c|c|c|c|c|c|c|c|c|c|c|c|c|c|c|c|c|c|}
\hline & \multicolumn{8}{|c|}{ Column 1} & \multicolumn{8}{|c|}{ Column 2} & \multicolumn{8}{|c|}{ Column 3} & \multicolumn{8}{|c|}{ Column 4} \\
\hline $\mathbf{M}$ & R1 & $\mathbf{R 2}$ & R3 & R4 & R5 & R6 & R7 & R8 & R1 & R2 & R3 & R4 & R5 & R6 & \begin{tabular}{|l} 
R7 \\
\end{tabular} & \begin{tabular}{|l|} 
R8 \\
\end{tabular} & R1 & R2 & R3 & R4 & R5 & |R6 & R7 & R8 & R1 & R2 & R3 & R4 & R5 & R6 & R7 & R8 \\
\hline $\mathbf{1}$ & 1 & 0 & 0 & 0 & 0 & 0 & 0 & 0 & 0 & 1 & 0 & 0 & 0 & 0 & 1 & 0 & 0 & 0 & 0 & 0 & 0 & 1 & 0 & 0 & 0 & 0 & 0 & 0 & 0 & 0 & 0 & 0 \\
\hline 2 & 0 & 1 & 0 & 0 & 0 & 0 & 0 & 0 & 0 & 0 & 1 & 0 & 0 & 0 & 0 & 1 & 0 & 0 & 0 & 0 & 0 & 0 & 1 & 0 & 0 & 0 & 0 & 0 & 0 & 0 & 0 & 0 \\
\hline \begin{tabular}{|l|}
3 \\
\end{tabular} & 0 & 0 & 1 & 0 & 0 & 0 & 0 & 0 & 0 & 0 & 0 & 1 & 0 & 0 & 0 & 0 & 1 & 0 & 0 & 0 & 0 & 0 & 0 & 1 & 0 & 0 & 0 & 0 & 0 & 0 & 0 & 0 \\
\hline 4 & 0 & 0 & 0 & 1 & 0 & 0 & 0 & 0 & 0 & 0 & 0 & 0 & 1 & 0 & 0 & 0 & 0 & 1 & 0 & 0 & 0 & 0 & 0 & 0 & 1 & 0 & 0 & 0 & 0 & 0 & 0 & 0 \\
\hline 5 & 0 & 0 & 0 & 0 & 1 & 0 & 0 & 0 & 0 & 0 & 0 & 0 & 0 & 1 & 0 & 0 & 0 & 0 & 1 & 0 & 0 & 0 & 0 & 0 & 0 & 1 & 0 & 0 & 0 & 0 & 0 & 0 \\
\hline $\begin{array}{ll}6 \\
\end{array}$ & 0 & 0 & 0 & 0 & 0 & 1 & 0 & 0 & 0 & 0 & 0 & 0 & 0 & 0 & 1 & 0 & 0 & 0 & 0 & 1 & 0 & 0 & 0 & 0 & 0 & 0 & 1 & 0 & 0 & 0 & 0 & 0 \\
\hline 7 & 0 & 0 & 0 & 0 & 0 & 0 & 1 & 0 & 0 & 0 & 0 & 0 & 0 & 0 & 0 & 1 & 0 & 0 & 0 & 0 & 1 & 0 & 0 & 0 & 0 & 0 & 0 & 1 & 0 & 0 & 0 & 0 \\
\hline 8 & 0 & 0 & 0 & 0 & 0 & 0 & 0 & 1 & 0 & 0 & 0 & 0 & 0 & 0 & 0 & 0 & 1 & 0 & 0 & 0 & 0 & 1 & 0 & 0 & 0 & 0 & 0 & 0 & 1 & 0 & 0 & 0 \\
\hline
\end{tabular}

Fig. 5. Optimum Golomb rulers of weight 4 , length 25 and cardinality 4

Fig. 6. (a): Construction of code matrix for 8 users 


\begin{tabular}{|c|c|c|c|c|c|c|c|c|c|c|c|c|c|c|c|}
\hline \multirow{8}{*}{$\mathrm{M} 1=$} & {$\left[\begin{array}{llll}1 & 0 & 0 & 0\end{array}\right]$} & \multirow{8}{*}{$\mathrm{M} 2=$} & {$\left[\begin{array}{llll}0 & 0 & 0 & 0\end{array}\right]$} & \multirow{8}{*}{ M3 = } & {$\left[\begin{array}{llll}0 & 0 & 1 & 0\end{array}\right]$} & \multirow{8}{*}{ M4 = } & {$\left[\begin{array}{llll}0 & 0 & 0 & 1\end{array}\right]$} & \multirow{8}{*}{ M5 = } & {$\left[\begin{array}{llll}0 & 0 & 0 & 0\end{array}\right]$} & \multirow{8}{*}{ M6 = } & ] & \multirow{8}{*}{$\mathrm{M} 7=$} & ] & \multirow{8}{*}{ M8 = } & {$\left[\begin{array}{llll}0 & 0 & 1 & 0\end{array}\right]$} \\
\hline & $\left|\begin{array}{llll}0 & 1 & 0 & 0\end{array}\right|$ & & $\left|\begin{array}{llll}1 & 0 & 0 & 0\end{array}\right|$ & & $\left|\begin{array}{llll}0 & 0 & 0 & 0\end{array}\right|$ & & $\left|\begin{array}{llll}0 & 0 & 1 & 0\end{array}\right|$ & & $\left|\begin{array}{llll}0 & 0 & 0 & 1\end{array}\right|$ & & $\mid \begin{array}{llll}0 & 0 & 0 & 0\end{array}$ & & $\left|\begin{array}{llll}0 & 0 & 0 & 0\end{array}\right|$ & & $\mid \begin{array}{llll}0 & 0 & 0 & 0\end{array}$ \\
\hline & 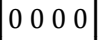 & & $\left|\begin{array}{llll}0 & 1 & 0 & 0\end{array}\right|$ & & $\begin{array}{llll}1 & 0 & 0 & 0\end{array}$ & & $\begin{array}{llll}0 & 0 & 0 & 0\end{array}$ & & 0010 & & $0 \begin{array}{llll}0 & 0 & 0 & 1\end{array}$ & & $\begin{array}{llll}0 & 0 & 0 & 0\end{array}$ & & $\left|\begin{array}{llll}0 & 0 & 0 & 0\end{array}\right|$ \\
\hline & $\begin{array}{llll}0 & 0 & 0 & 0\end{array}$ & & $\mid \begin{array}{lllll}0 & 0 & 0 & 0\end{array}$ & & \begin{tabular}{llll|l}
0 & 1 & 0 & 0
\end{tabular} & & $\begin{array}{llll}1 & 0 & 0 & 0\end{array}$ & & $\begin{array}{llll}0 & 0 & 0 & 0\end{array}$ & & 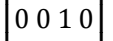 & & $0 \begin{array}{llll}0 & 0 & 0 & 1\end{array}$ & & $\begin{array}{lllll}0 & 0 & 0 & 0\end{array}$ \\
\hline & $\begin{array}{llll}0 & 0 & 0 & 0\end{array}$ & & $\begin{array}{llll}0 & 0 & 0 & 0\end{array}$ & & $\begin{array}{llll}0 & 0 & 0 & 0\end{array}$ & & $\begin{array}{llll}0 & 1 & 0 & 0\end{array}$ & & 1000 & & $\begin{array}{llll}0 & 0 & 0 & 1\end{array}$ & & 00010 & & $\begin{array}{lllll}0 & 0 & 0 & 1\end{array}$ \\
\hline & $\begin{array}{llll}0 & 0 & 1 & 0\end{array} \mid$ & & $\left|\begin{array}{llll}0 & 0 & 0 & 0\end{array}\right|$ & & $\left|\begin{array}{llll}0 & 0 & 0 & 0\end{array}\right|$ & & $\begin{array}{lllll}0 & 0 & 0 & 0\end{array}$ & & $\begin{array}{lllllllll}0 & 1 & 0 & 0\end{array}$ & & $\begin{array}{llll}1 & 0 & 0 & 0\end{array}$ & & $\begin{array}{llllllll}0 & 0 & 0 & 0\end{array}$ & & $\begin{array}{lllll}0 & 0 & 1 & 0\end{array}$ \\
\hline & $\begin{array}{lllll}0 & 1 & 0 & 0\end{array} \mid$ & & $\left|\begin{array}{lllll}0 & 0 & 1 & 0\end{array}\right|$ & & $\left|\begin{array}{llll}0 & 0 & 0 & 0\end{array}\right|$ & & $\begin{array}{llllll}0 & 0 & 0 & 0\end{array}$ & & $\begin{array}{llll}0 & 0 & 0 & 0\end{array}$ & & $\begin{array}{llll}0 & 1 & 0 & 0\end{array}$ & & 10000 & & $\begin{array}{llllll}0 & 0 & 0 & 0\end{array}$ \\
\hline & {$\left[\begin{array}{llll}0 & 0 & 0 & 0\end{array}\right]$} & & {$\left[\begin{array}{llll}0 & 1 & 0 & 0\end{array}\right]$} & & {$\left[\begin{array}{llll}0 & 0 & 1 & 0\end{array}\right]$} & & {$\left[\begin{array}{llll}0 & 0 & 0 & 0\end{array}\right]$} & & {$\left[\begin{array}{llll}0 & 0 & 0 & 0\end{array}\right]$} & & [ & & {$\left[\begin{array}{llll}0 & 1 & 0 & 0\end{array}\right]$} & & إ $1 \begin{array}{llll}1 & 0 & 0 & 0\end{array}$ \\
\hline
\end{tabular}

Fig. 6. (b): Codes for 8 users

From Figure 6(b), the code for matrix M1 will be $\left\{\lambda_{1}\left(\lambda_{2}\right.\right.$, $\left.\left.\lambda_{7}\right): \lambda_{6}\right\}$ and the code for matrix M2 will be $\left\{\lambda_{2}:\left(3, \lambda_{8}\right): \lambda_{7}\right\}$. Similarly the code for matrices M3....M32 can be constructed.

The code dimension can be determine as: if $r$ is the number of rows, $\mathrm{c}$ is the number of columns and $\mathrm{L}$ is the length of Golomb ruler then shifting of Golomb ruler is shown in figure 6 (a). The dimension of matrix is $\mathrm{r} \times \mathrm{c}$ and there are $\mathrm{r} \times \mathrm{c}-\mathrm{L}$ possible shifts. It shows that the number of shifts permitted is r $\times c$. So, the following equation should hold true to assure that matrix code set size $\mathrm{m}$ is equal to the number of rows in the matrices [12].

$$
\mathrm{r} \times \mathrm{c}-\mathrm{L} \geq \mathrm{r}-1
$$

Here, the length of Golomb ruler is $25, r=8$ (wavelengths) and $c=4$ (time slots). So the possible shifts are equal to $8 \times 4$ $25=7$.

\section{B. Probability of error in $W / T$ codes}

One dimensional codes spread either in time or frequency. Several types of 1-D codes are OOC, ZCC, Walsh code and Hadamard code. These codes can be characterized by $\left(\mathrm{L}_{\mathrm{t}}, \mathrm{W}, \lambda_{\mathrm{a}}, \lambda_{\mathrm{c}}\right)$. Where

- $\mathrm{N}$ is the number of code

- $\mathrm{L}_{\mathrm{t}}$ is the temporal length of the code

- $\mathrm{W}$ is the weight of the code (number of ones in the code)

- $\lambda \mathrm{a}$ is out of phase autocorrelation peak

- $\lambda \mathrm{c}$ is Cross correlation peak

The autocorrelation of one dimensional code $x(t)$ is defined as

$$
\begin{aligned}
& Z_{x, x}(l)=\sum_{n=0}^{L_{T}-1} x_{n} x_{(n+l) \bmod L_{T}} \\
& Z_{x, x}(l) \text { satisfies } \\
& \quad Z_{x, x}(l)\left\{\begin{array}{c}
=W \\
\leq \lambda_{a}
\end{array} \quad \text { if } 1 \leq l \leq L_{T}-1\right.
\end{aligned}
$$

The cross correlation of one dimensional code $\mathrm{x}(\mathrm{t})$ and $\mathrm{y}(\mathrm{t})$ is defined as

$$
\begin{aligned}
& Z_{x, y}(l)=\sum_{n=0}^{L_{T}-1} x_{n} y_{(n+l) \bmod L_{T}} \\
& Z_{x, y}(l) \text { satisfies }
\end{aligned}
$$

$$
Z_{x, y}(l) \leq \lambda_{c} \quad \text { if } 0 \leq l \leq L_{T}-1
$$

The autocorrelation of 2-dimensional codes $\mathrm{x}(\mathrm{t})$ is defined as

$$
Z_{x, x}(l)=\sum_{m=0}^{R-1}\left(\sum_{n=0}^{L_{T}-1} x_{m, n} x_{m,(n+l) \bmod L_{T}}\right)
$$

$Z_{x, x}(l)$ satisfies

$$
Z_{x, x}(l)\left\{\begin{array}{cc}
=W & \text { if } l=0 \\
\leq \lambda_{a} & \text { if } 1 \leq l \leq L_{T}-1
\end{array}\right.
$$

The cross correlation of 2-dimensional codes $\mathrm{x}(\mathrm{t})$ and $\mathrm{y}(\mathrm{t})$ is defined as

$$
\begin{aligned}
& Z_{x, y}(l)=\sum_{m=0}^{R-1}\left(\sum_{n=0}^{L_{T}-1} x_{m, n} y_{m,(n+l) \bmod _{T}}\right) \\
& Z_{x, y}(l) \text { satisfies } \\
& Z_{x, y}(l) \leq \lambda_{\mathrm{c}} \quad \text { if } 0 \leq l \leq L_{T}-1
\end{aligned}
$$

The probability of error/bit $\mathrm{P}_{\mathrm{e}}$ is given by

$$
P_{e}=\frac{1}{2} \sum_{i=T h}^{N-1}\left(\begin{array}{c}
N-1 \\
i
\end{array}\right)\left(\frac{W^{2}}{2 L_{T}}\right)^{i}\left(1-\frac{W^{2}}{2 L_{T}}\right)^{N-1-i}
$$

\section{SYSTEM SIMULATION}

The OCDMA system based on the optical codes is simulated by a commercial fiber optic simulation tool. The transmitter and receiver section of the OCDMA system based on W/T code is shown in Figure 7 and Figure 9 with their corresponding parameters in Table 1 and Table 2. In transmitter section, CW (Continuous Wave) laser is used as an optical source, Pseudo random Bit Sequence (PRBS) generator is used to generate random data and Mach-Zehnder Modulator to modulate the carrier signal generated by PRBS generator. Eight different wavelengths range from $1549.2 \mathrm{~nm}$ to 1554.8 $\mathrm{nm}$ with wavelength spacing $0.8 \mathrm{~nm}$ are multiplexed by WDM (Wavelength Division Multiplexer) from the laser array.

The modulated signal of each user is assigned a unique code by encoder which is shown in Figure 8. It consists of optical filters, time delays, splitter and combiner, the splitter splits the carrier signal and optical filters selects four specific wavelengths from the carrier signal to produce the encoded bit sequence. The time delay in the encoder places the selected pulses of specific wavelengths in appropriate time slot and combiner combines these four pulses to construct the encoded signal. 


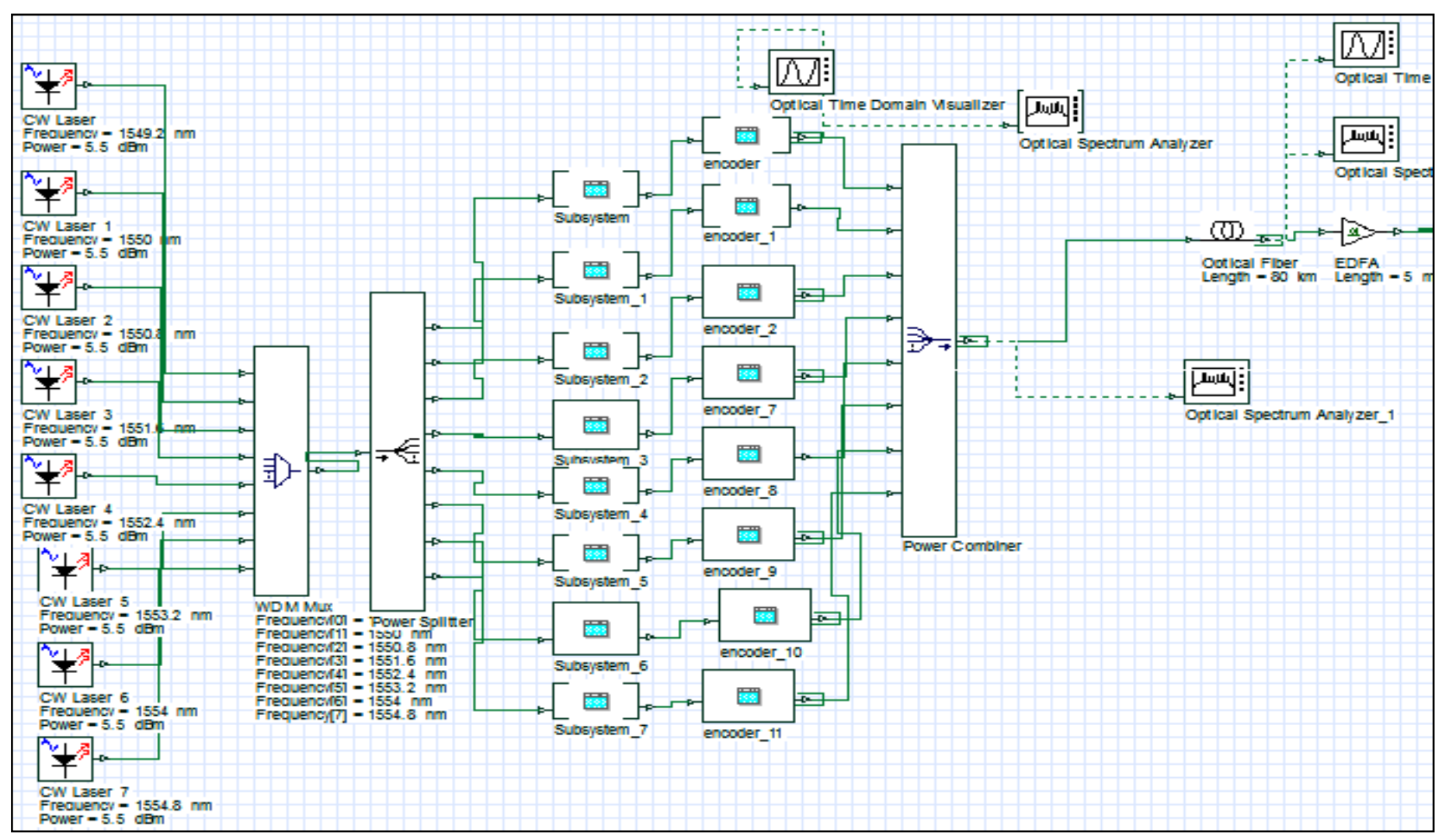

Fig. 7. OCDMA Transmitter block on Optisystem

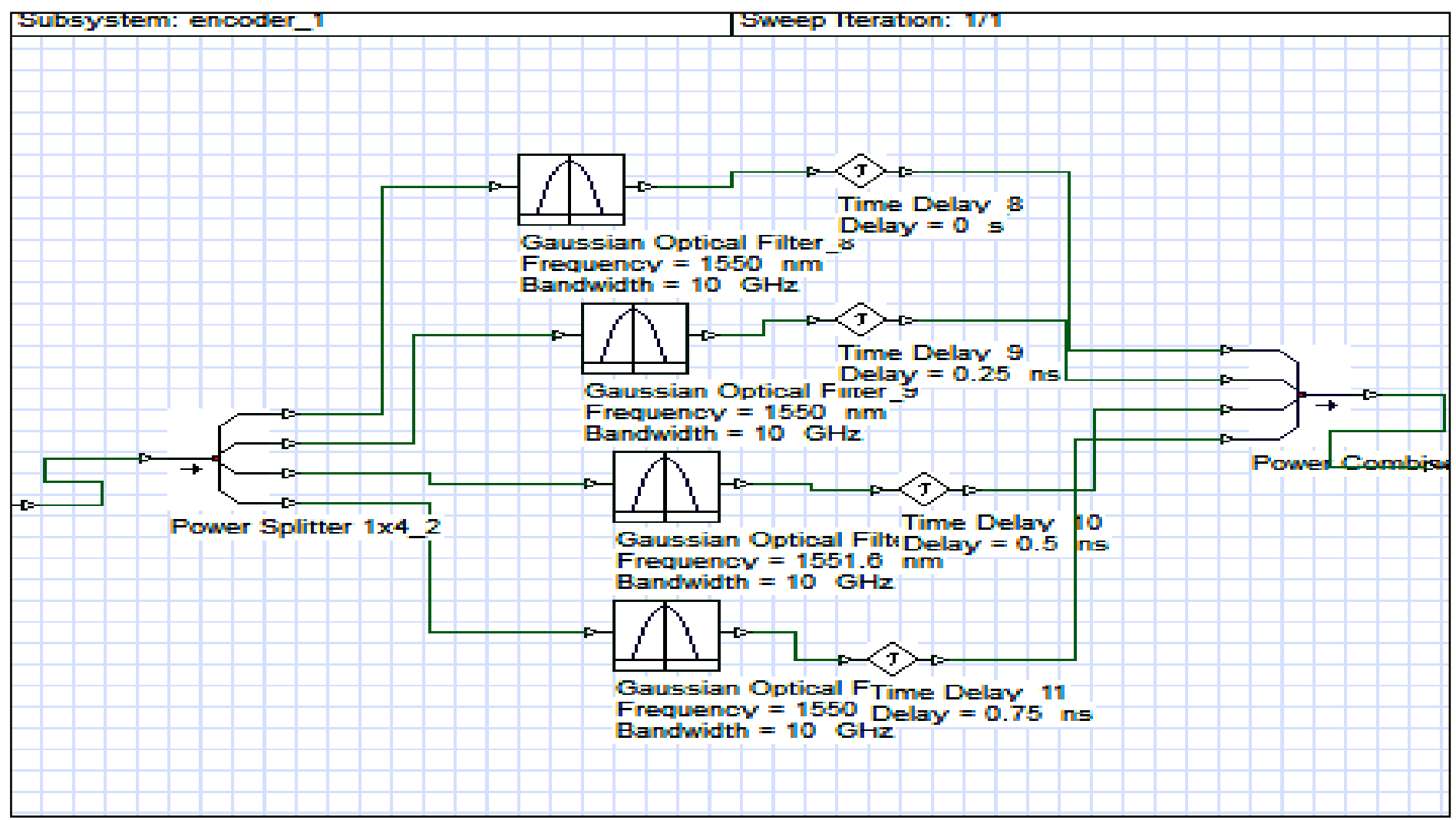

Fig. 8. Encoder Structure on Optisystem 
TABLE I. TRANSMITTER DESIGN PARAMETER

\begin{tabular}{|l|l|l|}
\hline Component & Parameter & Value \\
\hline \multirow{4}{*}{ CW Laser } & Wavelength & $1549.2 \mathrm{~nm}$ \\
\cline { 2 - 3 } & Spacing & $0.8 \mathrm{~nm}$ \\
\cline { 2 - 3 } & Power & $5.5 \mathrm{dBm}$ \\
\cline { 2 - 3 } & Line Width & $10 \mathrm{MHz}$ \\
\cline { 2 - 3 } & Initial Phase & 0 degree \\
\hline $\begin{array}{l}\text { Pseudo Random Bit } \\
\text { Sequence }\end{array}$ & Bit Rate & 1 and $1.25 \mathrm{Gbps}$ \\
\hline $\begin{array}{l}\text { Mach-Zehender } \\
\text { Modulator }\end{array}$ & Excitation ratio & $30 \mathrm{~dB}$ \\
\hline \multirow{3}{*}{ Fiber } & length & $50 \mathrm{~km}$ \\
\cline { 2 - 3 } & Attenuation & $0.2 \mathrm{~dB} / \mathrm{km}$ \\
\cline { 2 - 3 } & $\begin{array}{l}\text { Reference } \\
\text { wavelength }\end{array}$ & $1550 \mathrm{~nm}$ \\
\hline
\end{tabular}

The encoded data is combined and passed through single mode optical fiber (SMF) by considering length of $50 \mathrm{Km}$. Optical CDMA systems is designed which considers all practical impairments. The Table 3 represents time delay at 1 Gbps and $1.25 \mathrm{Gbps}$. If data rate is $1 \mathrm{Gbps}$ that means the duration of 1 bit is $1 \mathrm{~ns}$ and since four time slots are taken, so the duration for each time slots will be $0.25 \mathrm{~ns}$. For code M4 $\left\{\lambda_{4}: \lambda_{5}: \lambda_{2}: \lambda_{1}\right\}$, wavelength $\lambda_{4}$ is given in first time slot with zero delay, wavelength $\lambda_{5}$ is given in second time slot with 0.25 ns delay and wavelength $\lambda_{2}$ is given in third time slot with $0.5 \mathrm{~ns}$ delay and wavelength $\lambda_{1}$ is given in fourth time slot with
0.75 ns delay. Similarly delay for data rate 1.25 Gbps can also be calculated.

The optical signal is passed through the receiver section followed by decoder and photo detectors with low pass filter. The receiver extracts the information that is transmitted by transmitter. The decoder consists of optical filters and inverse time delays with respect to the transmitter that decodes a particular code as the corresponding encoder.

\section{TABLE II. RECEIVER DESIGN PARAMETER}

\begin{tabular}{|l|l|l|}
\hline Chip Period & $\begin{array}{l}\text { For 1Gbps bit rate } \\
\text { (ns) }\end{array}$ & For 1.25 Gbps bit rate (ns) \\
\hline T1 & 0 & 0 \\
\hline T2 & 0.25 & 0.2 \\
\hline T3 & 0.5 & 0.4 \\
\hline T4 & 0.75 & 0.6 \\
\hline
\end{tabular}

TABLE III. TIME DELAY AT 1 GBPS AND 1.25 GBPS

\begin{tabular}{|l|l|l|}
\hline Component & Parameter & Value \\
\hline \multirow{2}{*}{ Photo-detector } & Dark Current & $10 \mathrm{nA}$ \\
\cline { 2 - 3 } & Center frequency & $1552.5 \mathrm{~nm}$ \\
\hline \multirow{2}{*}{ Low Pass Bessel Filter } & Cutoff frequency & $8 \mathrm{GHz}$ \\
\cline { 2 - 3 } & Insertion loss & $0 \mathrm{~dB}$ \\
\hline
\end{tabular}

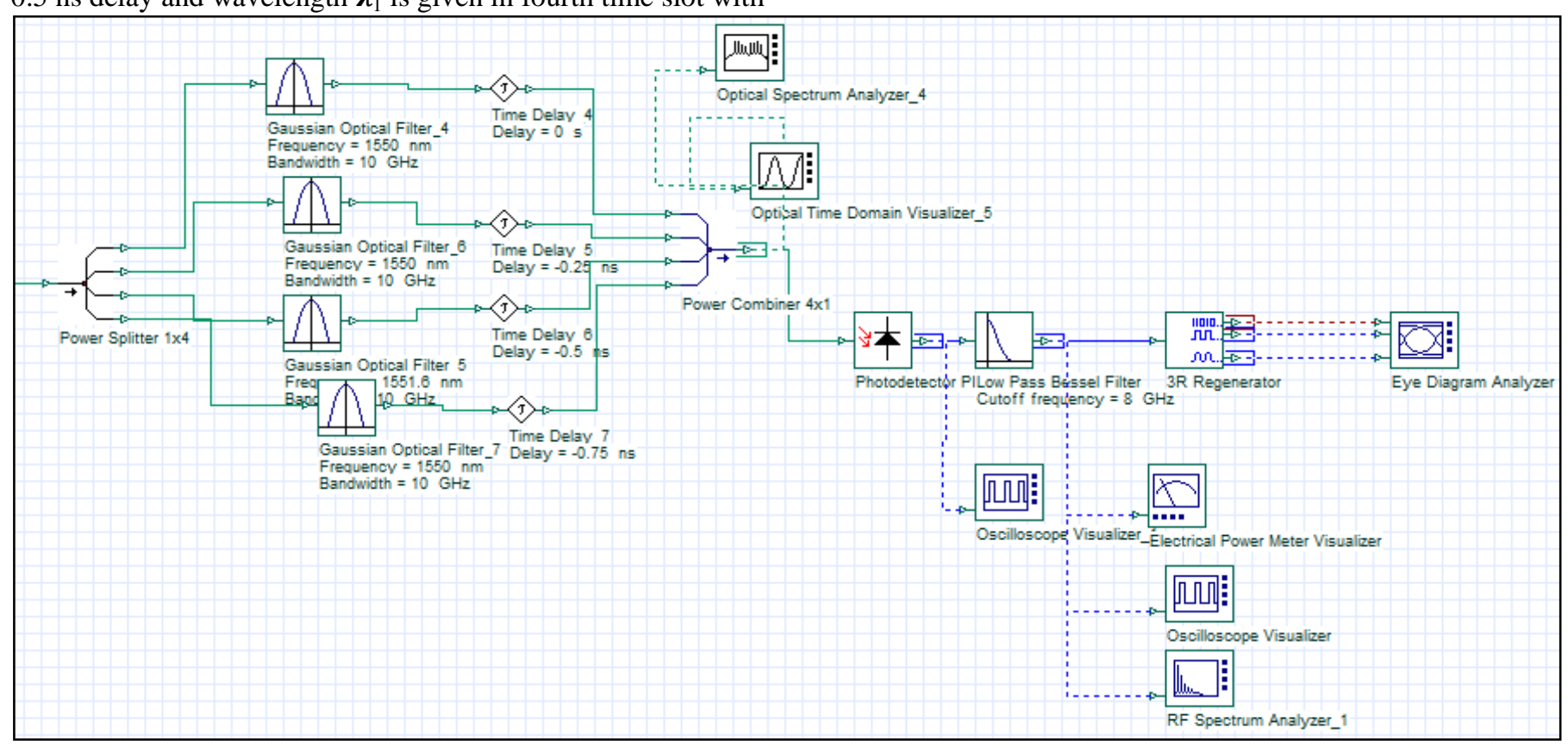

Fig. 9. OCDMA Receiver structure on Optisystem 


\section{RESULTS AND DISCUSSIONS}

The OCDMA system simulated on Optisystem uses CW laser centered at $1549.2 \mathrm{~nm}$.

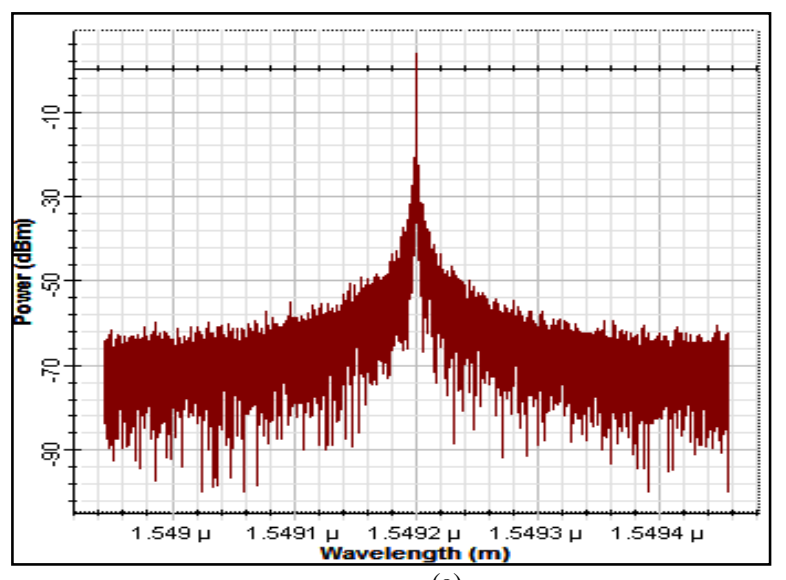

(a)

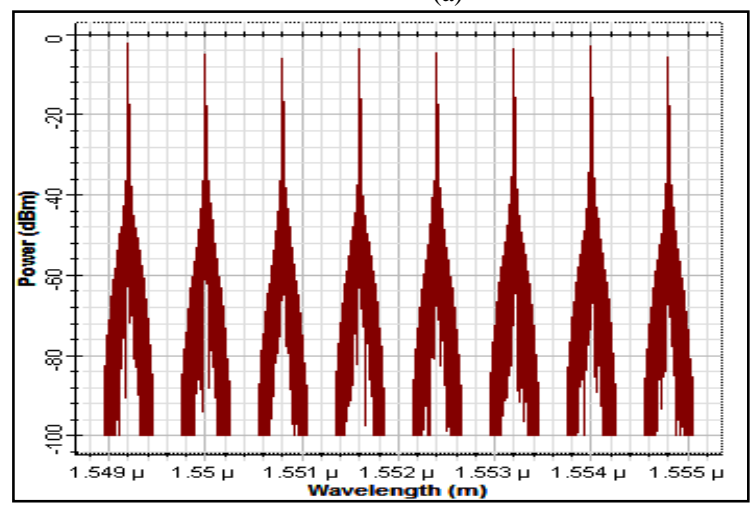

(b)

Fig. 10. CW Laser (a) Output of laser and (b) Multiplexed laser array spectrum

Figure 10 shows the $\mathrm{CW}$ laser output and eight multiplexed transmitted wavelengths. This multiplexed spectrum is modulated by user data with the help of MZM modulator. The output of MZM modulator is further encoded by different codes which are designed in Figure 6.

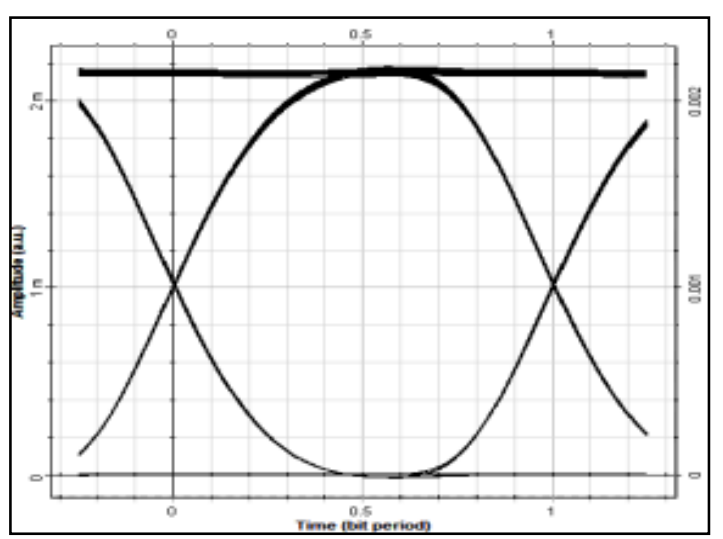

(a)
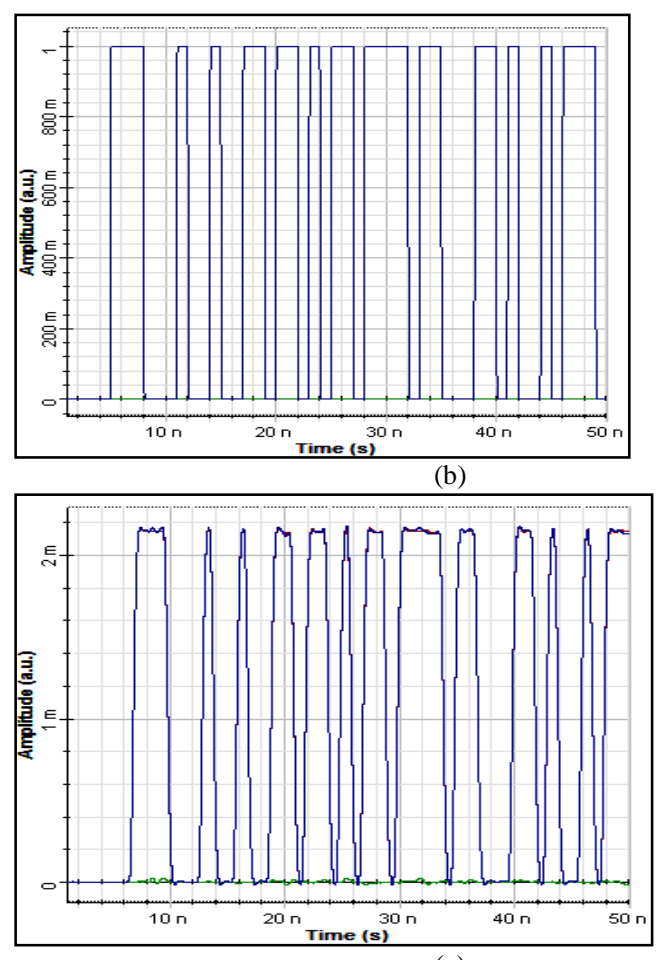

(c)

Fig. 11. Timing Diagram at 1 Gbps for 1 user (a) Eye Diagram (b) Transmitted Signal (c) Received Signal

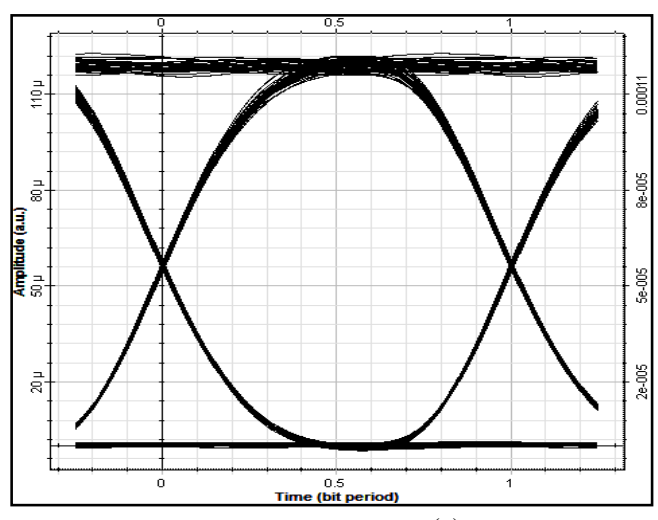

(a)

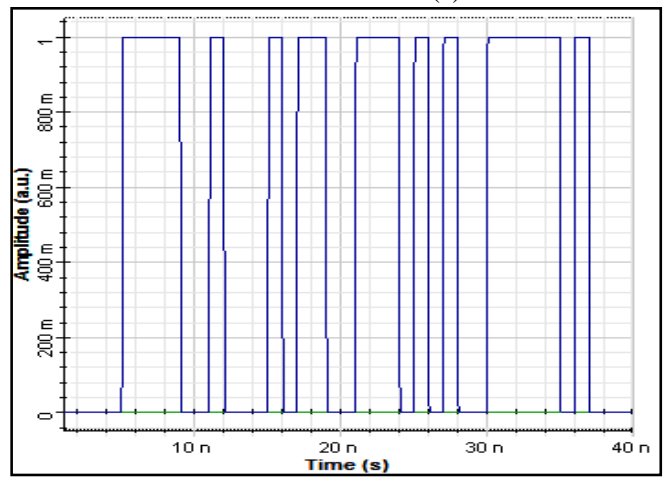

(b) 


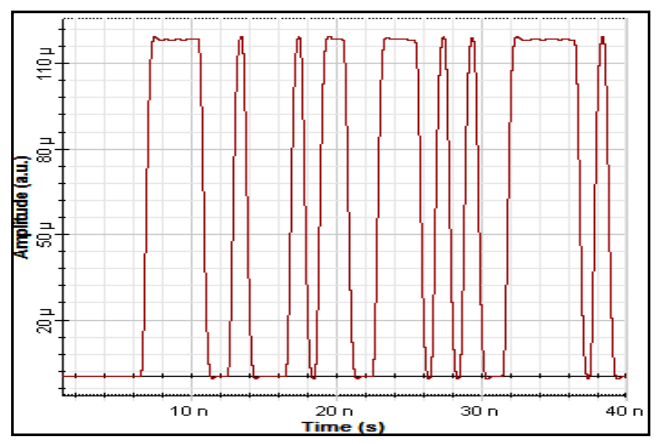

(c)

Fig. 12. Timing Diagram at 1 Gbps for 3 users (a) Eye Diagram (b) Transmitted Signal (c) Received Signal

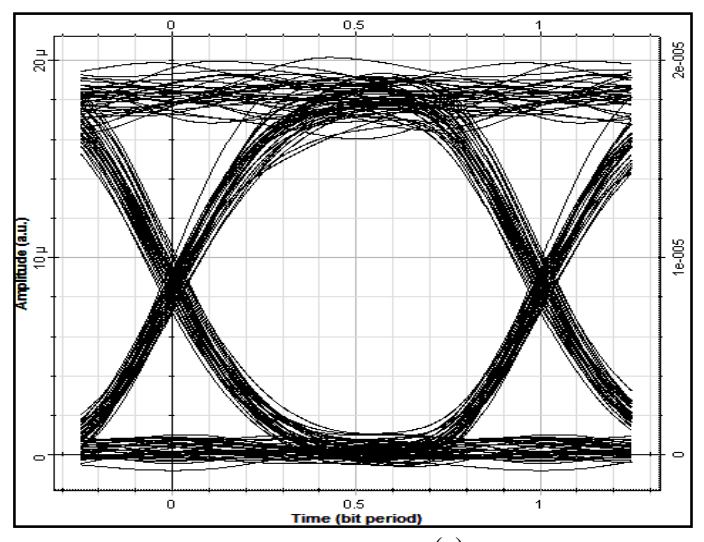

(a)
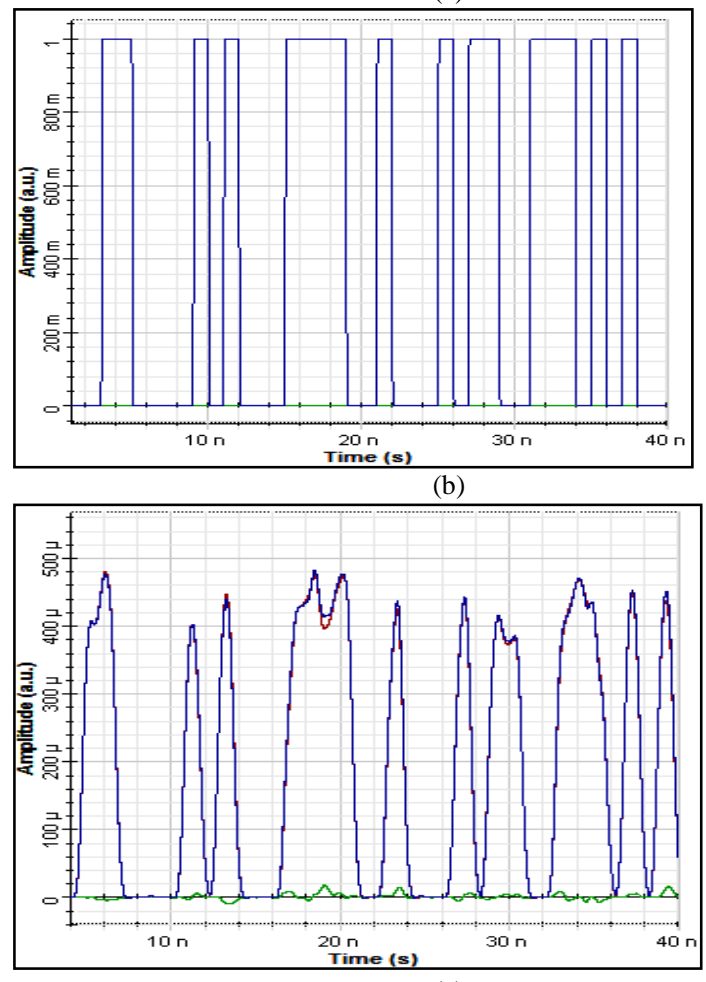

(c)

Fig. 13. Timing Diagram at 1 Gbps for 8 users (a) Eye Diagram (b) Transmitted Signal (c) Received Signal

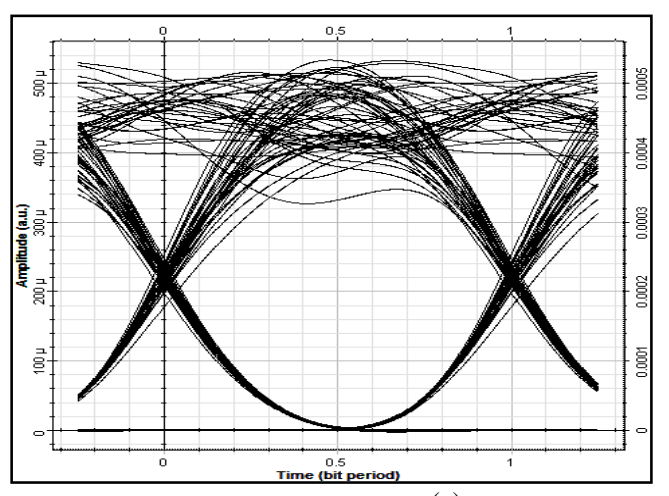

(a)

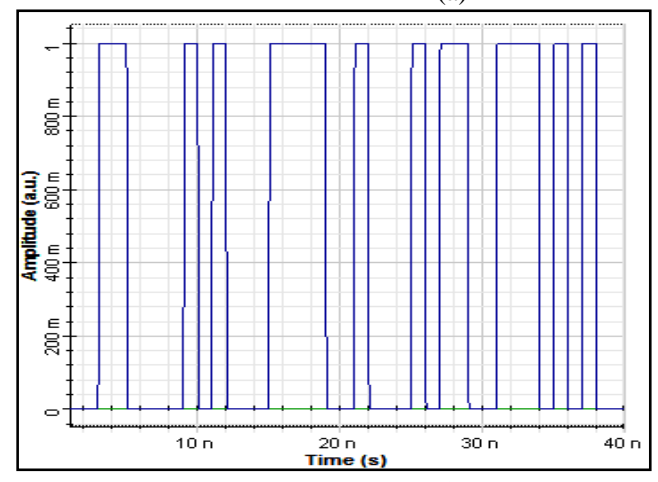

(b)

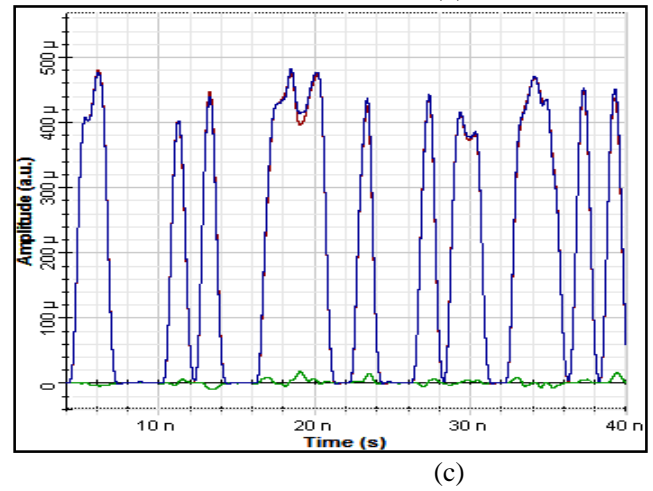

Fig. 14. Timing Diagram at $1 \mathrm{Gbps}$ for 12 users (a) Eye Diagram (b) Transmitted Signal (c) Received Signal

The demultiplexer demultiplexes the output which is given to the decoder section. The receiver receives the optical signal and converts it back to the electrical signal. The timing diagram at $1 \mathrm{Gbps}$ for $1,3,8$, and 12 users are shown in Figure 11 to Figure 14. The eye diagram allows visualizing the main parameters of electrical signal such as eye width, eye opening, quality factor, SNR etc. Figure 11- 14(a) represents the eye diagram. For an eye diagram measurement, noise on eye will cause the eye to close. Therefore the SNR is also directly indicated by amount of eye closer which represents that as the number of users increased the eye diagram starts closing means due to multiple access interference upper portion starts building noise. The Figure 11-14(b) represents the transmitted signal and Figure 11-14(c) represents the received signal. From Figure 11-14(a), it is revealed that as the number of users increase from 1 to 12 , noise is added and the eye height start decreasing and from Figure 11-14(c), it is noted that there is some noise at the amplitude of the signal which result that the 
amplitude decreases almost to $400 \mu$ (a.u.) which is initially at $2000 \mu$ (a.u.) and the received signal is also dispersed in time domain as it passes through the fiber. Similarly signal can be received at $1.5 \mathrm{Gbps}$ but as the data rate has been increased from $1 \mathrm{Gbps}$ to $1.25 \mathrm{Gbps}$, MAI further increases.

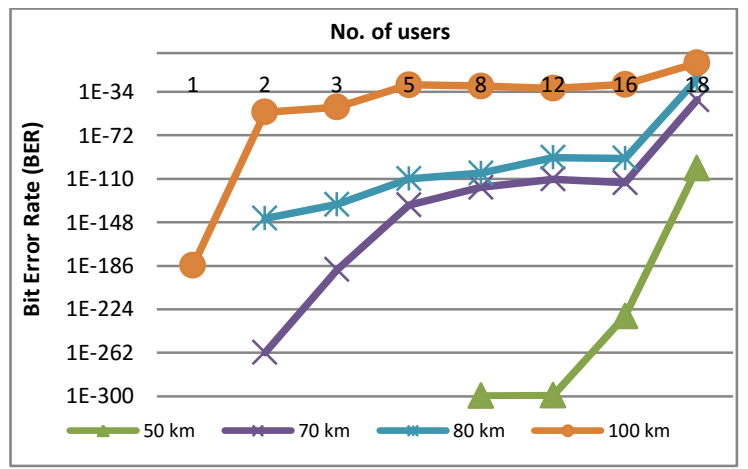

Fig. 15. BER vs. Number of users for different fiber length at $1 \mathrm{Gbps}$

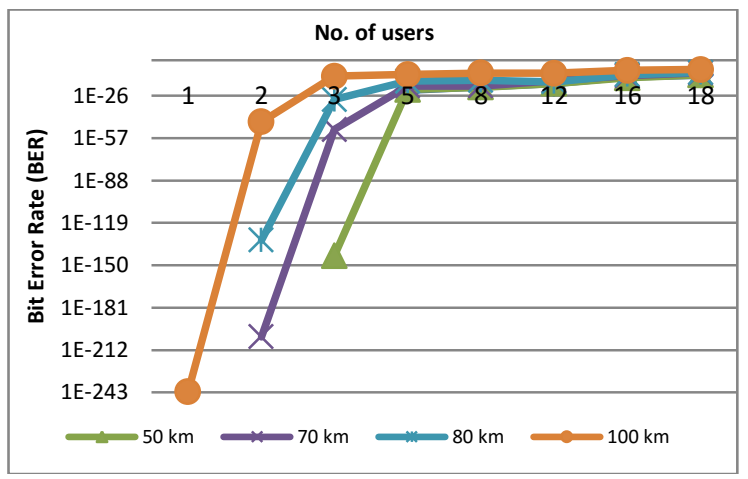

Fig. 16. BER vs. No. of users for different fiber length at $1.25 \mathrm{Gbps}$

The comparative analysis between BER and number of users for various lengths of fiber at $1 \mathrm{Gbps}$ and $1.25 \mathrm{Gbps}$ is shown in Figure 15 and Figure 16 respectively. It is observed that as the length of the fiber increases the bit error rate also increases. For three number of simultaneous users in $1 \mathrm{Gbps}$ system, the bit error rate increases from 0 to $1 \mathrm{e}^{-40}$ as the fiber length has been increased from 50 to $100 \mathrm{~km}$ whereas for $1.25 \mathrm{Gbps}$ system, the bit error rate increases from $1 \mathrm{e}^{-150}$ to $1 \mathrm{e}^{-}$ 15 .

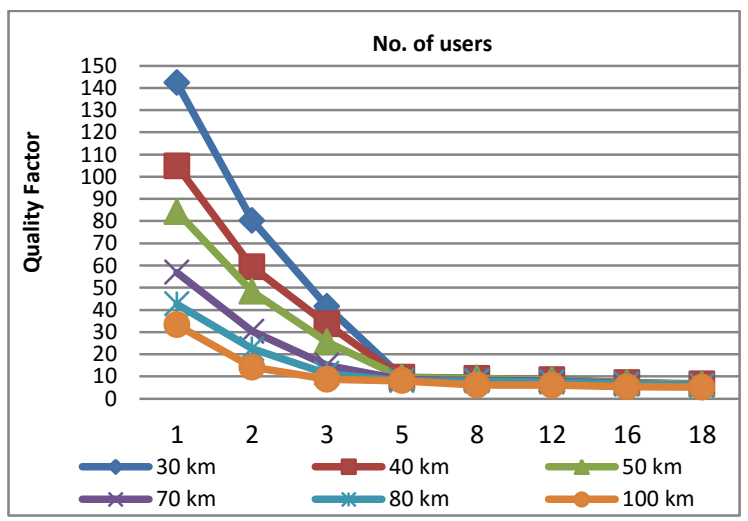

Fig. 17. $\mathrm{Q}$ factor vs. number of users for different fiber length at $1 \mathrm{Gbps}$

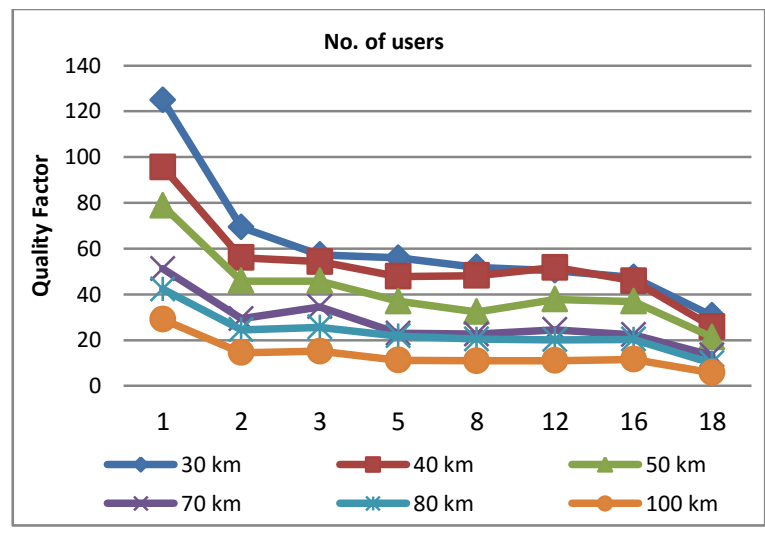

Fig. 18. Q factor vs. number of users for different fiber length at $1.25 \mathrm{Gbps}$

The comparative analysis between quality factor and number of users for various lengths of fiber at $1 \mathrm{Gbps}$ and 1.25 Gbps are presented in Figure 17 and Figure 18 respectively. It is observed that as the length of the fiber increases the quality factor decreases. For two simultaneous users in $1 \mathrm{Gbps}$ system, the quality factor decreases from 80 to 10 as the fiber length increases from 30 to $100 \mathrm{Km}$ whereas for $1.25 \mathrm{Gbps}$ system, the quality factor decreases from 70 to 8 . Similarly at data rate of $1.25 \mathrm{Gbps}$, the performance deteriorates. Hence, the analysis reveals that as the number of simultaneous users in the system increase, MAI become dominant with degrading in amplitude of received signal. For practical implementation of the optical CDMA based on the proposed codes, the optical fiber loop can be used instead of time delay line.

\section{CONCLUSION}

One dimensional code have disadvantage of increasing code length with the increment of number of users. The simulated design of $2 \mathrm{D} \mathrm{W} / \mathrm{T}$ OCDMA code shows that cardinality of 2D code is high. The performance of OCDMA system has been evaluated with increasing number of users in the form of quality factor and BER. It has been observed that as the number of user's increases, the eye opening decreases which results in decrease in amplitude due to noise. At data rate of $1 \mathrm{Gbps}$ as the length of the fiber increases from $50 \mathrm{Km}$ to $100 \mathrm{Km}$, the bit error rate shows the significant increment from 0 to $\mathrm{e}^{-40}$ with decrement of quality factor from 40 to 5 for 3 users.

\section{REFERENCES}

[1] J. A. Salehi, "Code division multiple access techniques in optical fiber networks part I: Fundamental principles," IEEE Transactions Communication, vol. 37, no. 8, pp. 824-833, 1989.

[2] R. K. Fan Chung and J. A. Salehi, "Optical Orthogonal Codes: Design, Analysis and Applications," IEEE Transactions on Information Theory, May, vol. 35, no. 3, pp. 595-604, 1989.

[3] A. J. Mendez, R. M. Gagliardi, H. X. C. Feng, J. P. Heritage, and J. M. Morookian, "Strategies for realizing optical CDMA for dense, high speed, long span, optical network applications', Journal of Lightwave Technology, vol. 18, no. 12, pp. 1685-1696, 2000.

[4] A. J. Mendez, S. Kuroda, R. M. Gagliardi, and E. Garmire, "Generalized temporal code division multiple access (CDMA) for optical communication," SPIE Proceeding, vol. 1, no. 125, pp. 287-291, 1989.

[5] V. J. Hernandez, A. J. Mendez, V. Bennett, R. M.Gagliardi, and W. J. Lennon, "Design and performance analysis of wavelength/time (W/T) matrix codes for optical CDMA," Journal of Lightwave Technology, vol. 21, no. 11, pp. 2524-2533, 2003. 
[6] H. Heo, S. Min, Y. H. Won, Y. Yeon, B. K. Kim and B. W. Kim, "A new family of 2-D wavelength-time spreading codes for optical codedivision multiple-access system with balanced detection", IEEE Photon Technology Letter vol. 8, pp. 2189-2191, 2004.

[7] Y., Yeon, B. K. Kim, S. C. Cho, S. J. Park and B. W. Kim, "Two dimensional wavelength/time optical cdma system adopting balanced modified pseudo random noise matrix codes", U.S. Patent application, 0100338 A1, 2005.

[8] S. P. Wan, and Y. Hu, "Two-dimensional optical CDMA differential system with prime/OOC codes", IEEE Photon Technology Letter vol. 13, pp. 1373-1375, 2001.

[9] V. J. Hernandez, A. J. Mendez, C. V. Bennett, R. M. Gagliardi and W. J. Lennon, "Bit-Error-Rate Analysis of a 16-User Gigabit Ethernet Optical-
CDMA (OCDMA) technology Demonstrator Using Wavelength/ Time Codes," IEEE Photonics Technology Letters, vol. 17, no. 12, pp. 27842786, 2005.

[10] J. Faucher, R. Adams, L. R. Chen and D. V. Plant, "Multiuser OCDMA system demonstrator with full CDR using a novel OCDMA receiver," IEEE Photon Technology Letter, vol. 17, no. 5, pp. 1115-1117, 2005.

[11] P. Patel, V. Baby, L. Xu, D. Rand, I. Glesk, and P. R. Prucna1, “A scalable wavelength hopping and time spreading optical CDMA system," IEEE LEOS-03 Proceeding, pp. 1048-1049, 2003.

[12] R. Poboril, J. Latal, P. Koudelka, J. Vitasek, P. Siska, J. Skapa, and V. Vasinek, "A Concept of a Hybrid WDM/TDM Topology using the Fabry-Perot Laser in the Optiwave Simulation Environment," Optics and Optoelectronics, vol.9, no.4, pp. 167-178, 2011. 